IJBPAS, December, 2021, 10(12): 4703-4707

ISSN: $2277-4998$

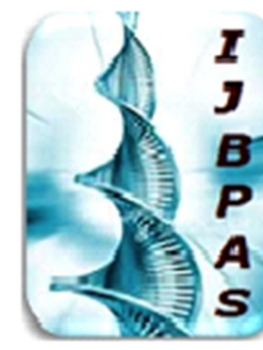

International Journal of Biology, Pharmacy

and Allied Sciences (IJBPAS)

'A Bridge Betuben Caboratory and QRendo'

WwW.iibpas.com

\title{
A CASE REPORT OF PARATHYROID ADENOMAAS A CAUSE FOR PATHOLOGICAL FRACTURE
}

\section{MADAV PRAVEEN R ${ }^{1 *}$, RAGHURAM ${ }^{2}$, AND BASKARAN PK}

1: Junior Resident, Department of General Surgery, Sree Balaji Medical College and Hospital, Chrompet, Chennai, India

2: Senior Resident, Department of General Surgery, Sree Balaji Medical College and Hospital, Chrompet, Chennai, India

3: Professor, Department of General Surgery, Sree Balaji Medical College and Hospital,

Chrompet, Chennai, India

*Corresponding Author: Madav Praveen R: E Mail: madhavpraveen@gmail.com

Received 28 ${ }^{\text {th }}$ March 2021; Revised 28 ${ }^{\text {th }}$ April 2021; Accepted 25 ${ }^{\text {th }}$ May 2021; Available online $1^{\text {st }}$ Dec. 2021

https://doi.org/10.31032/IJBPAS/2021/10.12.5797

\begin{abstract}
Case primary hyperparathyroidismwith pathological fracture of the shaft ofthe left femur, treated with parathyroidectomy,is reported. A female aged 40 presentedwith pathological fracture of the left femur and a swelling in the neck, just cephalic to the medial end of the clavicle. Investigation, showedElevated levels of serum parathormone, calcium and ALPUSH revealed a hetero echoic lesion corresponding to the neckand a swelling, suggestive of left inferior parathyroid adenoma. The lesion was removedPatient improved postoperatively, is currently on follow-up.
\end{abstract}

Keyword: Primary hyperparathyroidism, Pathological fracture, Parathyroid adenoma, Parathyroidectomy

\section{INTRODUCTION}

The various signs of hyperparathyroidism pathological fractures, acute pancreatitis and include renalstone disease, peptic ulcer, psychological manifestations. 


\section{TREATMENT}

A patient of primary hyperparathyroidism presenting with a pathological fracture of the left femur is reported here.

\section{CASE REPORT}

A 40 year old female patient presented to the out-patient department with history of accidental fall at workplace followed by deformity of the left lower limb. She was not able to stand on her feet or walk. She was found to have a fracture of the left femur (Figure 1).

On examination, patient bed-ridden with a small swelling, measuring $5 \mathrm{~cm} \mathrm{x} 3 \mathrm{~cm}$ in the root of the neck on the left side, just cephalad to the medial end of the clavicle (Figure 2).

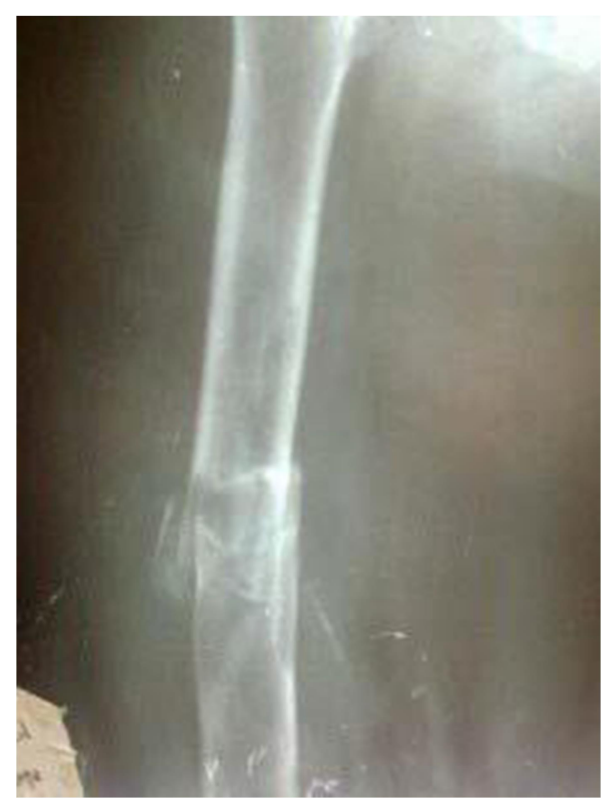

Figure 1: Pathological fracture - shaft of left femur

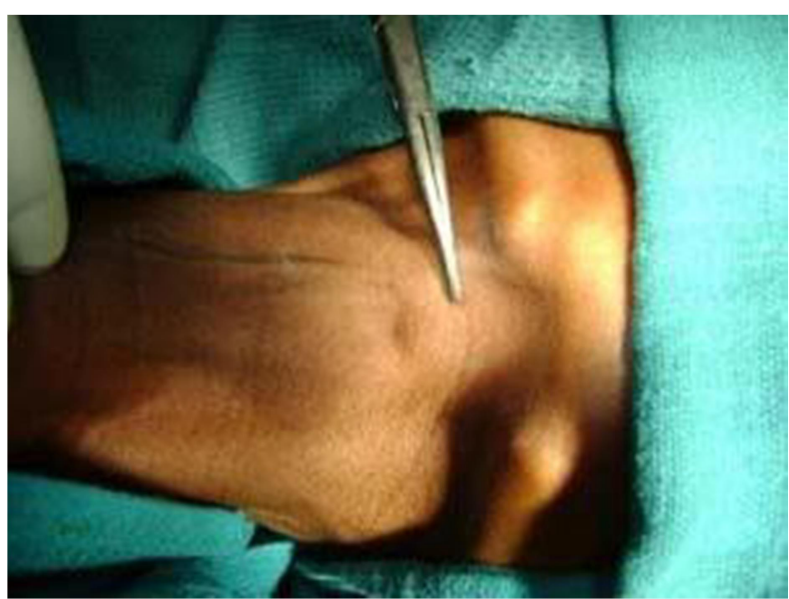

Figure 2: Swelling at the root of the neck onthe left side the left lower limb extendingfrom the thigh to the foot 
Pre-operative levels of parathormone, lower pole of the left lobe of the thyroid calcium and alkaline phosphatase was assessed. Serum parathormonewas $1280 \mathrm{pg} / \mathrm{ml}$ (normal range 15-65),calcium was $12.2 \mathrm{mg} / \mathrm{dl}$ (normal range $8.0-10.0$ ) and alkaline phosphatase was $800 \mathrm{IU} / \mathrm{ml}$ (normal range 48 - 406). Ultrasonogram of the neck revealed a heteroechoic lesion, measuring $3 \mathrm{~cm} \times 2 \mathrm{~cm} \times 2.5 \mathrm{~cm}$ in the left para-tracheal (Figure 3).

\section{TREATMENT}

Patient was planned for parathyroidectomy.In the procedure it showed enlarged parathyroid was anterior to the recurrent laryngeal nerve, suggesting that it is the left inferior parathyroid gland. The enlarged gland was removed (Figure 4).

region, lateral to esophagus, posterior to

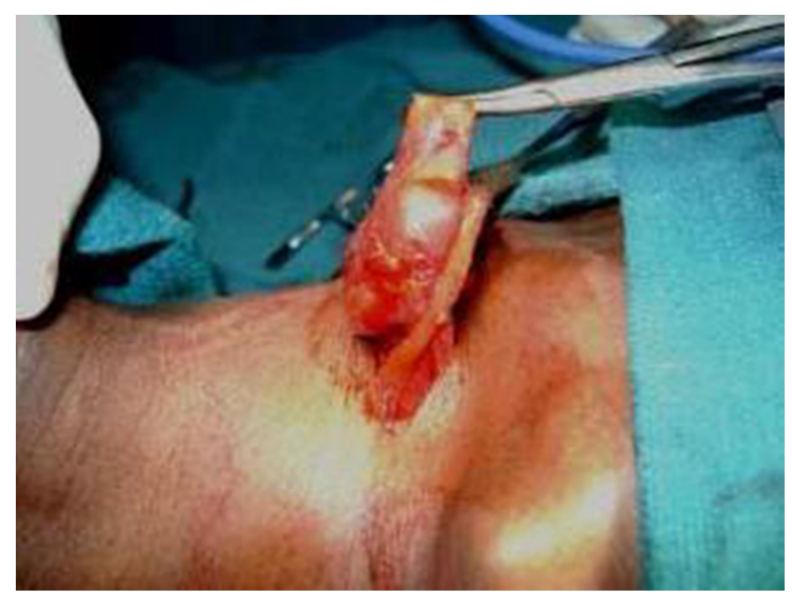

Figure 3: Parathyroid adenoma removed out of the wound

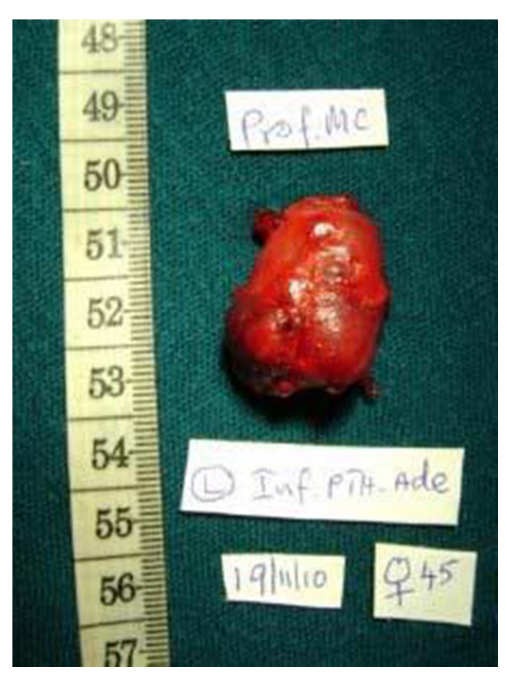

Figure 4: gross specimen 


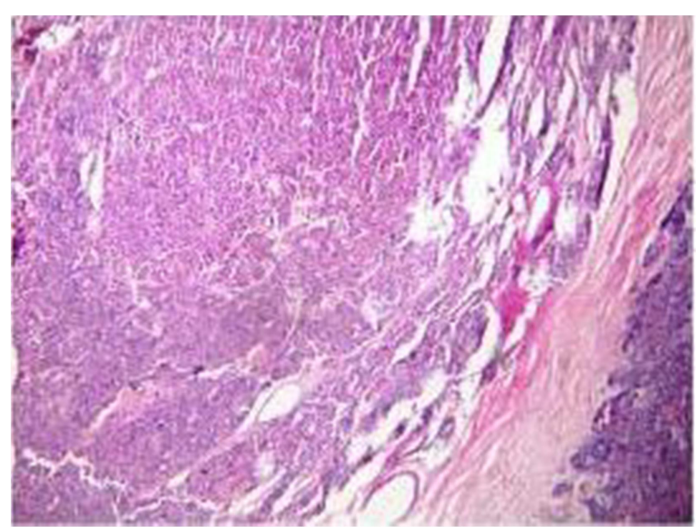

Figure 5: Parathyroid adenoma HPE

Histopathological examination confirmed the diagnosis of parathyroid adenoma, from the compressed normal parathyroid tissue surrounding the neoplasma (Figure 5). In the post-operative period, the serum levels of calcium dropped to $8.6 \mathrm{mg} / \mathrm{dl}$ on the first post-operative day, dropping further to 7.0 $\mathrm{mg} / \mathrm{dl}$ on the second post-operative day. Hypocalcemia was treated with intravenous calcium infusion for 3 days, followed by oral calcium and vitamin D3 supplements. At present, oral calcium and vitamin D3 supplementation is given.

\section{DISCUSSION}

Primary hyperparathyroidism is of threetypes

- type 1, pathological fractures and bone disease; type 2, renal stones and pancreatic calculi and type 3, asymptomatic with biochemical evidence of hyperparathyroidism, presentation with combination of more than one type is not infrequent [1].
This patient had type 1 hyperparathyroidism, with multiple pathological fractures. Biochemical evidence of hyperparathyroidism was present in the patient. A palpable nodule in the left side of the neck was presentUltra sonogram of the neck revealedmixed echogenic lesion in the proximityof the left lower pole of thyroid, whichwas suggestive of the diagnosis suspected [2]. Sestamibi scan is gold standard for localization of hyper-functioning parathyroid. However, ultrasonogram of the neck also shows anatomical localization of the parathyroid tumor as was evident in this case. In this patient, focused parathyroidectomy was performed, with excision of the enlarged inferior parathyroid gland, without exploring the other parathyroids.

\section{REFERENCES}

[1] Hussain A, Mahmood H, Geddoa E, Hamish M, Reda AH. Parathyroid- 
adenoma and hyper-calcemia in apatient presenting with multiple pathological fractures of the longbones. Int J Surg, 2006; 6(6): 465-8.
[2] Wang SM, Li XX, Chang DQ, Wang JS, Huang XL. Surgical treatmentfor patients with primary hyperparathyroidism. Zhonghua WaiKey Zha hi. 2004; 42(9): 532-9. 